\title{
Rural-urban differences in the use of postnatal care services in Malawi
}

\section{Original Article}

\author{
Kennedy Machira ${ }^{1,2}$, Martin E. Palamuleni ${ }^{2}$ \\ ${ }^{1}$ Lilongwe University of Agriculture and Natural Resource, Faculty of Development Studies, \\ P.O. Box 219, Lilongwe, Malawi.
}

${ }^{2}$ Population Research Unit, Faculty of Human and Social Sciences, North West UniversityMafikeng, P.O. Box X2046, Mmabatho, 2735, Republic of South Africa.

\begin{abstract}
Background: In Malawi, women's postpartum care services often remain underutilized despite the efforts of the government to promote the use of maternal healthcare. Consequently, maternal mortality and morbidity are persistently high.

Aim: The aim of the study is to examine the factors associated with women's use of postpartum care services in urban areas as compared with the rural areas in Malawi.

Materials and Methods: The study used data of 2010 Malawi Demographic and Health Survey. A two-staged approach was used in data analysis where the logistic regression and multinomial regression methods were used to identify first the determinants of use and second to classify the determinants associated with timing of women's use of postpartum care service in the country.

Results: Of the 13776 women that constituted the sample, 7018 (50.9\%) reported to use postpartum care services. Caesarean delivery in both urban [odds ratio $(\mathrm{OR})=3.98 ; 95 \%$ confidence interval (CI): 2.27- 6.98] and rural settings $(\mathrm{OR}=3.56$; 95\% CI: 2.91-4.36) greatly increased women's likelihood of using postpartum care. On the contrary, problems of availability of health services decreased women's likelihood of using postpartum care services in both urban $(\mathrm{OR}=0.75$; 95\% CI: 0.57-0.97) and rural settings (OR=0.87; 95\% CI: 0.80-0.93). Further, pregnancy complications, lower levels of women's education, difficulties to access available healthcare facilities and low media exposure were significantly associated with women's delay in using postpartum care services in rural Malawi compared with their counterparts who used the services within $24 \mathrm{~h}$ after childbirth.

Conclusion: In both urban and rural settings, women's use of postnatal care services remains low. The influence of low socioeconomic and service quality factors was prominent in rural areas more than in urban areas. This information is significant to health policy stakeholders to understand ways which can be adopted in order to enhance quality and use of postnatal care services. Therefore, there is need to promote women-centred and community-based awareness in order to enhance the use of postnatal care in urban and rural areas, if maternal health outcomes are to improve in Malawi.
\end{abstract}

Received: 05 July 2016, Accepted: 03 January 2017

Key Words: Caesarean delivery, Malawi, postpartum care, pregnancy complications.

Corresponding Author: Kennedy Machira, Ph.D., Lilongwe University of Agriculture and Natural Resource, Faculty of Development Studies, Lilongwe, Malawi, Tel.: +27843190091, E-mail: kmachila30@gmail.com

ISSN: 0013-2446, Vol. 92, No.1

\section{INTRODUCTION}

In the 21 st century, maternal mortality remains one of the highest and greatest health challenges facing the developing world ${ }^{[1]}$. Over the past 50 years, the problem has been gradually declining across countries within sub-Saharan Africa registering one in 51 lifetime risk of dying from causes related to pregnancy relative to one in 5100 chance for a woman from the developed world ${ }^{[2]}$. Such maternal health challenge exists despite numerous commitment and investment in healthcare systems aimed at promoting quality of care $^{[2-4]}$. Maternal health outcome still remains a major challenge in most sub-Saharan African countries, and Malawi is included ${ }^{[5]}$.

Previous studies have attributed this worsening maternal health conditions not only to poor access to maternal healthcare facilities, but also to subsequent missed opportunities to access robust healthcare services due to the inadequate capacity of the health facilities to meet the emergent maternal health needs ${ }^{[6-8]}$.

In view of this maternal health challenge, the government of Malawi initiated numerous programs aimed 
at promoting maternal health situation in the country. For instance, The Millennium Development Goal, Focussed Antenatal Care Service Delivery, Abuja Declaration on Healthcare Investment Roadmap to accelerate reduction of neonatal and maternal deaths ${ }^{[9,10]}$. However, despite these initiatives aimed at improving maternal health outcome through facility-based support, poor pregnancy outcome still continues, in addition to low women healthcare service utilization after childbirth.

Studies that investigated the relative factors associated with low care utilization among women attributed the situation to inadequate laboratory equipment in the healthcare facility and other resource constrains which negatively compromise quality of care in developing countries including Malawi ${ }^{[11-14]}$. While, much has been written on the determinants of maternal healthcare utilization from the perspective of antenatal and childbirth delivery care, comparatively little is known on the determinants of postpartum use among women in rural and urban settings.

This study seeks to investigate the determinants affecting women's use of postpartum care services and the factors associated with the timing of their use of postpartum care services in Malawi by using the data of the Malawi Demographic and Health Survey 2010.

\section{MATERIALS AND METHODS}

\section{Data}

The study used the 2010 Malawi Demographic and Health Survey data which is the national representative survey of women in the reproductive age between 15 and 49 years. The data comprised 23020 women of which 13 776 were reported to have at least one birth in the last 3 years preceding the survey. Among them, 7018 (50.9\%) women reported to have utilized postpartum care services at that time.

\section{Analytical strategy}

The study used a two-staged approach in which two dependent variables were used to estimate the determinants of women's use of postnatal care in rural and urban settings in Malawi. First, women utilization status of postpartum care which was defined and coded 1 if a woman attended a postpartum care facility and 0 for otherwise. Therefore, as an outcome that is dichotomously defined, a binary logistic regression model was used to estimate the correlates of women's use of postpartum care in urban and rural settings. In addition, women who were reported to have used postpartum care services were classified into three categories based on the timing in which they accessed and used the healthcare services as follows: immediate postpartum access, defined as women who used the services within $24 \mathrm{~h}$ after childbirth; intermediate postpartum access, for those who used the services between day 1 and 6 after childbirth; and delayed postpartum care access, defining those women who utilized the services from a period of 1 week or more after childbirth. As the variable is trichotomously defined, a multinomial regression model was used to estimate the determinants associated with the timing of postpartum care use among women in rural and urban settings in Malawi.

\section{Variables used in the study}

The study explanatory variables were as follows: antenatal care (ANC) frequency, mode of delivery, distance to health facility, availability of transport, knowledge about pregnancy complications, age at first birth, maternal education, occupational status, number of living children, availability of healthcare services, exposure to media and women autonomy to seek their own healthcare. The same categories recorded in the DHS were used in this study. The study used Stata 13.0 for the analysis (Stata Corp., College Station, Texas, USA) in which $P$ value 0.05 was used to test the statistical significance of the differences between variables. In order to access the data, a request was launched to the DHS administrator, in return an authorization was granted to access and download the data from the measure DHS website.

\section{RESULTS}

\section{Background characteristics of women associated with the use of postnatal care service}

Table 1 displays the bivariate results of the state of women's use of postpartum care services and the independent variables in both rural and urban settings in Malawi. Of the 23020 nationally sampled women in which 13776 reported to have delivered their babies at the time of the survey, 7018 (50.9\%) utilized postpartum care service facilities after childbirth. Of these women, 4370 $(62.3 \%)$ received postpartum care within $24 \mathrm{~h}, 1691$ (24\%) between 1 and 6 days and $957(13.6 \%)$ a week or more after childbirth. This represented a total of $984(14.1 \%)$ rural women and 6084 (85.9\%) urban women. 
Table 1: The association between women characteristics and postpartum care utilisation, Malawi, DHS 2010

\begin{tabular}{|c|c|c|c|c|c|c|c|c|c|c|}
\hline \multirow[t]{2}{*}{ Variables } & & & \multicolumn{8}{|c|}{ Postpartum care utilization } \\
\hline & \multicolumn{4}{|c|}{ Urban } & & & \multicolumn{4}{|c|}{ Rural } \\
\hline \multirow[t]{4}{*}{ Total Number of Women } & \multicolumn{3}{|c|}{$1,454(100 \%)$} & & & \multicolumn{3}{|c|}{$12,322(100 \%)$} & & \\
\hline & No & & Yes & & & No & & Yes & & \\
\hline & $\mathrm{N}$ & $\%$ & $\mathrm{~N}$ & $\%$ & & N\% & $\%$ & $\mathrm{~N}$ & $\%$ & \\
\hline & 470 & 32.3 & 984 & 67.7 & p-value & 6,28 & 51 & 6,034 & 49 & p-value \\
\hline \multicolumn{11}{|l|}{ ANC frequency } \\
\hline$\leq 3$ & 255 & 34.6 & 481 & 65.4 & 0.12 & 3,706 & 54.2 & 3,135 & 45.8 & $0.000^{* * *}$ \\
\hline 4 or higher & 215 & 29.9 & 503 & 70.1 & & 2,582 & 47.1 & 2,899 & 52.9 & \\
\hline \multicolumn{11}{|l|}{ Caesarean Delivery } \\
\hline No & 455 & 34.5 & 863 & 65.5 & $0.000 * * *$ & 6,160 & 52.5 & 5,584 & 47.5 & $0.000 * * *$ \\
\hline Yes & 15 & 11.0 & 121 & 89.0 & & 128 & 22.1 & 450 & 77.9 & \\
\hline \multicolumn{11}{|l|}{$\begin{array}{l}\text { Distance to Health } \\
\text { facility }\end{array}$} \\
\hline Not a problem & 318 & 30.4 & 729 & 69.6 & $0.018 * *$ & 2,125 & 47.1 & 2,388 & 52.9 & $0.000 * * *$ \\
\hline Problem & 152 & 37.3 & 255 & 62.7 & & 4,163 & 53.3 & 3,646 & 46.7 & \\
\hline \multicolumn{11}{|l|}{ Transport availability } \\
\hline Not a problem & 312 & 29.7 & 739 & 70.3 & 0.051 & 2,303 & 47.7 & 2,528 & 52.3 & $0.000 * * *$ \\
\hline Problem & 158 & 39.2 & 245 & 60.8 & & 3,985 & 53.2 & 3,506 & 46.8 & \\
\hline \multicolumn{11}{|l|}{$\begin{array}{l}\text { Pregnancy } \\
\text { complications }\end{array}$} \\
\hline No & 105 & 43.4 & 137 & 56.6 & $0.0 .2 * * *$ & 1,739 & 64.6 & 954 & 35.4 & $0.000 * * *$ \\
\hline Yes & 365 & 30.1 & 847 & 69.9 & & 4,549 & 47.2 & 5,080 & 52.8 & \\
\hline \multicolumn{11}{|l|}{ Age at first birth } \\
\hline$<20$ & 321 & 35.4 & 586 & 64.6 & 0.06 & 4,634 & 51.8 & 4,312 & 48.2 & $0.016^{* *}$ \\
\hline 20 or higher & 149 & 27.2 & 398 & 72.8 & & 1,654 & 49.0 & 1,722 & 51.0 & \\
\hline \multicolumn{11}{|l|}{ Women education } \\
\hline Illiterate & 38 & 37.6 & 63 & 62.4 & 0.08 & 1,220 & 57.4 & 907 & 42.6 & $0.000 * * *$ \\
\hline Primary & 277 & 37.0 & 471 & 63.0 & & 4,492 & 51.6 & 4,210 & 48.4 & \\
\hline Secondary and higher & 155 & 25.6 & 450 & 74.4 & & 576 & 38.6 & 917 & 61.4 & \\
\hline \multicolumn{11}{|l|}{ Occupation status } \\
\hline Unemployed & 169 & 35.7 & 305 & 64.3 & $0.032 * *$ & 1,397 & 51.7 & 1,307 & 48.3 & $0.000 * * *$ \\
\hline Farming & 68 & 37.6 & 113 & 62.4 & & 3,430 & 52.6 & 3,091 & 47.4 & \\
\hline Other & 233 & 29.2 & 566 & 70.8 & & 1,461 & 47.2 & 1,636 & 52.8 & \\
\hline \multicolumn{11}{|l|}{ Living children } \\
\hline $0-2$ & 270 & 33.7 & 532 & 66.3 & 0.91 & 2,437 & 49.3 & 2,511 & 50.7 & $0.042 * *$ \\
\hline $3-4$ & 129 & 29.0 & 316 & 71.0 & & 2,171 & 51.5 & 2,047 & 48.5 & \\
\hline 5 or higher & 71 & 34.3 & 136 & 65.7 & & 1,680 & 53.2 & 1,476 & 46.8 & \\
\hline \multicolumn{11}{|l|}{$\begin{array}{l}\text { Aavailability of health } \\
\text { care service }\end{array}$} \\
\hline Problem & 309 & 29.9 & 726 & 70.1 & 0.059 & 3,090 & 49.2 & 3,185 & 50.8 & $0.000 * * *$ \\
\hline Not a problem & 161 & 38.4 & 258 & 61.6 & & 3,198 & 52.9 & 2,849 & 47.1 & \\
\hline Exposure to media & & 0.0 & & 0.0 & & & & & & \\
\hline $\begin{array}{l}\text { Neither radio nor } \\
\text { television }\end{array}$ & 165 & 39.1 & 257 & 60.9 & $0.000 * * *$ & 2,993 & 52.7 & 2,690 & 47.3 & $0.000 * * *$ \\
\hline
\end{tabular}




\begin{tabular}{|c|c|c|c|c|c|c|c|c|c|c|}
\hline Either radio or television & 188 & 31.5 & 409 & 68.5 & & 3,032 & 50.4 & 2,978 & 49.6 & \\
\hline Radio and television & 117 & 26.9 & 318 & 73.1 & & 263 & 41.8 & 366 & 0.0 & \\
\hline \multicolumn{11}{|l|}{ Women autonomy } \\
\hline No & 434 & 31.6 & 939 & 68.4 & $0.012 * *$ & 5,509 & 50.8 & 5,325 & 49.2 & 0.67 \\
\hline Yes & 36 & 44.4 & 45 & 55.6 & & 779 & 52.4 & 709 & 47.6 & \\
\hline
\end{tabular}

$* * * p<0.001, * * p<0.05$

There were noticeable differences in the factors affecting women's use of postnatal care services in both settings. For instance, caesarean section (CS), distance to healthcare facilities, pregnancy complications, occupational status, exposure to media and women autonomy were significant predictors of urban women's use of postnatal care services, based on bivariate analysis. In rural settings, all factors with the exception of women autonomy significantly influence women's use of postnatal care services in the country.

\section{Multivariate results}

Table 2 illustrates the binary logistic regression model estimates associated with women's use of postnatal care in rural and urban settings in Malawi. In both settings, $\mathrm{CS}$ [odds ratio $(\mathrm{OR})=3.98$ in urban and $\mathrm{OR}=3.56$ in rural areas, $P<0.001]$ and knowledge of pregnancy complications $(\mathrm{OR}=1.58$ in urban areas and $\mathrm{OR}=1.66$ in rural areas, $P<0.001)$ were the significant factors associated with higher likelihood of use. In urban areas, two more factors, apart from CS and pregnancy complications, were significantly associated with higher use; having 3-4 living children $(\mathrm{OR}=1.46)$ and women exposure to either radio or television $(\mathrm{OR}=1.36)$. In rural areas, attaining a secondary school education or higher $(\mathrm{OR}=1.31, P<0.001)$ increased the likelihood of utilization of postnatal care services.

Table 2: Binary logistic regression results of factors influencing women's use of postnatal care in rural and urban settings, Malawi, DHS 2010

\begin{tabular}{|c|c|c|c|c|}
\hline \multirow[t]{2}{*}{ Variables } & \multicolumn{2}{|c|}{ Urban } & \multicolumn{2}{|c|}{ Rural } \\
\hline & OR & $95 \% \mathrm{CI}$ & OR & $95 \% \mathrm{CI}$ \\
\hline \multicolumn{5}{|l|}{ ANC frequency } \\
\hline$\leq 3$ & 1 & & 1 & \\
\hline 4 or higher & 1.09 & $0.87-1.37$ & $1.20 * * *$ & $1.11-1.28$ \\
\hline \multicolumn{5}{|l|}{ Caesarean delivery } \\
\hline No & 1 & & 1 & \\
\hline Yes & $3.98 * * *$ & $2.27-6.98$ & $3.56^{* * *}$ & $2.91-4.36$ \\
\hline \multicolumn{5}{|l|}{ Distance to health facility } \\
\hline Not a problem & 1 & & 1 & \\
\hline Problem & 0.97 & $0.69-1.36$ & $0.78 * * *$ & $0.70-0.86$ \\
\hline \multicolumn{5}{|l|}{ Transport availability } \\
\hline Not a problem & 1 & & 1 & \\
\hline Problem & 0.79 & $0.56-1.11$ & $0.90^{* *}$ & $0.81-1.00$ \\
\hline \multicolumn{5}{|l|}{ Pregnancy complications } \\
\hline No & 1 & & 1 & \\
\hline Yes & $1.58 * *$ & $1.21-2.08$ & $1.66^{* * *}$ & $1.53-1.80$ \\
\hline \multicolumn{5}{|l|}{ Age at first birth } \\
\hline$<20$ & 1 & & 1 & \\
\hline 20 or higher & 1.16 & $0.90-1.49$ & 0.98 & $0.91-1.07$ \\
\hline \multicolumn{5}{|l|}{ Women education } \\
\hline Illiterate & 1 & & 1 & \\
\hline Primary & 0.84 & $0.61-1.15$ & $0.91 * *$ & $0.83-0.99$ \\
\hline Secondary and higher & 1.23 & $0.85-1.78$ & $1.31 * * *$ & $1.14-1.50$ \\
\hline \multicolumn{5}{|l|}{ Occupation status } \\
\hline Unemployed & 1 & & 1 & \\
\hline
\end{tabular}




\begin{tabular}{|c|c|c|c|c|}
\hline Farming & 0.90 & $0.63-1.30$ & $0.85 * * *$ & $0.78-0.92$ \\
\hline Other & 1.16 & $0.91-1.49$ & 0.97 & $0.88-1.08$ \\
\hline \multicolumn{5}{|l|}{ r of living children } \\
\hline $0-2$ & 1 & & & \\
\hline $3-4$ & $1.46^{* *}$ & $1.12-1.89$ & $0.87 * *$ & $0.80-0.95$ \\
\hline 5 or more & 1.20 & $0.85-1.69$ & $0.85^{* *}$ & $0.78-0.93$ \\
\hline $\begin{array}{l}\text { care service } \\
\text { ility }\end{array}$ & & & & \\
\hline ot a problem & 1 & & & \\
\hline Problem & $0.75^{* *}$ & $0.59-0.97$ & $0.87 * * *$ & $0.80-0.93$ \\
\hline \multicolumn{5}{|l|}{ Ire to media } \\
\hline $\begin{array}{l}\text { ither radio nor } \\
\text { television }\end{array}$ & 1 & & & \\
\hline radio or television & $1.36^{* *}$ & $1.04-1.77$ & 0.96 & $0.89-1.03$ \\
\hline o and television & 1.17 & $0.85-1.62$ & 1.13 & $0.95-1.35$ \\
\hline \multicolumn{5}{|l|}{ h autonomy } \\
\hline No & 1 & & & \\
\hline Yes & 0.74 & $0.46-1.20$ & 1.05 & $0.94-1.18$ \\
\hline
\end{tabular}

$* * * p<0.001, * * p<0.05, \mathrm{CI}=$ Confidence Interval

With regard to lower use, in both areas, the common factor which was significantly associated with lower likelihood of use is the existence of problems associated with the availability of services $(\mathrm{OR}=0.75, P<0.05$ in urban and $\mathrm{OR}=0.87, P<0.001$ in rural areas). In rural areas alone, the following factors were significantly associated with lower use: distance challenge $(\mathrm{OR}=0.78, P<0.001)$, problems of transport to the services $(\mathrm{OR}=0.90, P<0.05)$, women attainment of primary education $(\mathrm{OR}=0.91$, $P<0.05)$, increased number of living children $(\mathrm{OR}=0.87$, $P<0.001$ for $3-4$ children and $\mathrm{OR}=0.85, \mathrm{P}<0.05$ for five and more children) and earning a living through farming as an occupation $(\mathrm{OR}=0.85, P<0.001)$.

The multinomial logistic regression model results of use of postpartum care services between 1 and 6 days after childbirth are presented in Tables 3 and 4. In Table 3 , women in both rural and urban areas, who earned their living through farming $(\mathrm{OR}=0.55)$, were significantly less likely to use postpartum care services between 1 and 6 days after childbirth compared with their counterparts who used the services within $24 \mathrm{~h}$ after childbirth.

In rural setting, women who had an ANC frequency of at least 4 or more $(\mathrm{OR}=0.87)$, knew complication during pregnancy $(\mathrm{OR}=0.8)$, were aged 20 year or higher at first birth $(\mathrm{OR}=0.86)$, of low education $(\mathrm{OR}=0.71)$, earn their living through farming $(\mathrm{OR}=0.85)$, had 3-4 living children $(\mathrm{OR}=0.84)$ and who experienced challenges to the availability of healthcare facilities $(\mathrm{OR}=0.75)$ were significantly less likely to use the postnatal care services between 1 and 6 days after childbirth compared with those who use postnatal care within $24 \mathrm{~h}$ after childbirth. On the contrary, women who had an access to both radio and television $(\mathrm{OR}=1.32)$ were significantly more likely to use postnatal care services between land 6 days after childbirth relative to those who used the services within $24 \mathrm{~h}$ after childbirth.

Women's use of postnatal care between 1 week or higher after childbirth as compared with use within $24 \mathrm{~h}$ after childbirth is presented in Table 4. It shows that in urban settings, use after 1 week was significantly lower when the following factors were present: problem of distance to access healthcare $(\mathrm{OR}=0.46)$, women's knowledge of pregnancy complications $(\mathrm{OR}=0.64)$ and access to either radio or television $(\mathrm{OR}=0.62)$.

In rural settings, a lot of factors reduced women's likelihood to use maternal healthcare services between 1 week or higher after childbirth including: problems of distance to access healthcare $(\mathrm{OR}=0.81)$, lack of knowledge of pregnancy complications $(\mathrm{OR}=0.62)$, low level of women's education $(\mathrm{OR}=0.62)$, higher number of living children (0.74) and women's exposure to either radio or television $(\mathrm{OR}=0.84)$; all were associated with significant low likelihood of women's use of postnatal care. On the contrary, delivery by $\mathrm{CS}(\mathrm{OR}=1.52)$ was associated with significantly higher use of postnatal care services after 1 week or more after childbirth compared with those who used postnatal care within $24 \mathrm{~h}$ after childbirth.

In both settings, the factors in common that were associated with significant lower use of postnatal care services in the country were: problems with distance to health facility, knowledge of pregnancy complications and accessing either radio or television. Table 4 illustrates the detailed results. 
Table 3: Multinomial logistic regression results of the factors influencing postnatal care utilization between 1-6 days after childbirth, Malawi, DHS 2010

\begin{tabular}{|c|c|c|c|c|}
\hline \multirow[t]{3}{*}{ Variables } & \multicolumn{4}{|c|}{ Postpartum Care between [1-6 days] Vs $<24$ hours after childbirth } \\
\hline & \multicolumn{2}{|c|}{ Urban } & \multicolumn{2}{|c|}{ Rural } \\
\hline & OR & S.E. & OR & S.E \\
\hline \multicolumn{5}{|l|}{ Antenatal frequency } \\
\hline \multicolumn{5}{|l|}{$\leq 3(\mathrm{R})$} \\
\hline 4 or higher & 0.86 & 0.15 & $0.87 * *$ & 0.06 \\
\hline \multicolumn{5}{|l|}{ Caesarean section } \\
\hline \multicolumn{5}{|l|}{ No $(\mathrm{R})$} \\
\hline Yes & 1.46 & 0.22 & 1.06 & 0.12 \\
\hline \multicolumn{5}{|l|}{ Distance to health facility } \\
\hline \multicolumn{5}{|l|}{ Not a problem $(\mathrm{R})$} \\
\hline Problem & 1 & 0 & 0.92 & 0.09 \\
\hline \multicolumn{5}{|l|}{ Transport availability } \\
\hline \multicolumn{5}{|l|}{ Not a problem $(\mathrm{R})$} \\
\hline Problem & 0.74 & 0.24 & 0.99 & 0.09 \\
\hline \multicolumn{5}{|l|}{ Pregnancy complications } \\
\hline \multicolumn{5}{|l|}{ No $(\mathrm{R})$} \\
\hline Yes & 0.75 & 0.19 & $0.8 * * *$ & 0.08 \\
\hline \multicolumn{5}{|l|}{ Age at first birth } \\
\hline \multicolumn{5}{|l|}{$<20(\mathrm{R})$} \\
\hline 20 or higher & 1.02 & 0.16 & $0.86^{* *}$ & 0.07 \\
\hline \multicolumn{5}{|l|}{ Women education } \\
\hline \multicolumn{5}{|l|}{ Illiterate (R) } \\
\hline Primary & 0.9 & 0.22 & $0.71 * * *$ & 0.08 \\
\hline Secondary and higher & 0.77 & 0.25 & 0.83 & 0.11 \\
\hline \multicolumn{5}{|l|}{ Occupation status } \\
\hline \multicolumn{5}{|l|}{ Unemployed (R) } \\
\hline Farming & $0.55^{* *}$ & 0.28 & $0.85^{* *}$ & 0.07 \\
\hline Other & 1.16 & 0.16 & 0.93 & 0.09 \\
\hline \multicolumn{5}{|l|}{ Number of living children } \\
\hline \multicolumn{5}{|l|}{$0-2(\mathrm{R})$} \\
\hline $3-4$ & 0.99 & 0.17 & $0.84 * *$ & 0.07 \\
\hline 5 or higher & 1.05 & 0.23 & 0.96 & 0.08 \\
\hline \multicolumn{5}{|l|}{$\begin{array}{l}\text { Health care service } \\
\text { availability }\end{array}$} \\
\hline \multicolumn{5}{|l|}{ Not a problem $(\mathrm{R})$} \\
\hline Problem & 0.96 & 0.17 & $0.75 * * *$ & 0.06 \\
\hline \multicolumn{5}{|l|}{ Exposure to media } \\
\hline $\begin{array}{l}\text { Neither radio nor } \\
\text { television }(\mathrm{R})\end{array}$ & & & & \\
\hline Radio or television & 0.87 & 0.18 & 0.89 & 0.06 \\
\hline Radio and television & 1.19 & 0.21 & $1.32 * *$ & 0.13 \\
\hline Women autonomy & & & & \\
\hline No $(\mathrm{R})$ & & & & \\
\hline Yes & 1.25 & 0.35 & $0.8^{* *}$ & 0.11 \\
\hline
\end{tabular}

${ }^{* * *} p<0.001,{ }^{* *} p<0.05$; OR: Odds Ratio, SE: Standard Errors, R: reference category 
Table 4: Multinomial logistic regression results of the factors influencing postnatal care utilization one week or higher after childbirth, Malawi, DHS 2010

\begin{tabular}{|c|c|c|c|c|}
\hline \multirow[t]{3}{*}{ Variables } & \multicolumn{4}{|c|}{ Postpartum Care [ 1 week or higher ) Vs $<24$ hours after childbirth } \\
\hline & \multicolumn{2}{|c|}{ Urban } & \multicolumn{2}{|c|}{ Rural } \\
\hline & OR & S.E. & OR & S.E. \\
\hline \multicolumn{5}{|l|}{ Antenatal frequency } \\
\hline \multicolumn{5}{|l|}{$\leq 3(\mathrm{R})$} \\
\hline 4 or higher & 0.72 & 0.18 & 0.94 & 0.08 \\
\hline \multicolumn{5}{|l|}{ Caesarean section } \\
\hline \multicolumn{5}{|l|}{ No (R) } \\
\hline Yes & 1.17 & 0.29 & $1.52 * * *$ & 0.13 \\
\hline \multicolumn{5}{|l|}{ Distance to health facility } \\
\hline \multicolumn{5}{|l|}{ Not a problem $(\mathrm{R})$} \\
\hline Problem & $0.46^{* * *}$ & 0.29 & $0.81^{* *}$ & 0.11 \\
\hline \multicolumn{5}{|l|}{ Transport availability } \\
\hline \multicolumn{5}{|l|}{ Not a problem $(\mathrm{R})$} \\
\hline Problem & 1.6 & 0.28 & 0.96 & 0.11 \\
\hline \multicolumn{5}{|l|}{ Pregnancy complications } \\
\hline \multicolumn{5}{|l|}{ No (R) } \\
\hline Yes & $0.62 * *$ & 0.22 & $0.62 * * *$ & 0.09 \\
\hline \multicolumn{5}{|l|}{ Age at first birth } \\
\hline \multicolumn{5}{|l|}{$<20(\mathrm{R})$} \\
\hline 20 or higher & 1.01 & 0.2 & 0.94 & 0.09 \\
\hline \multicolumn{5}{|l|}{ Women education } \\
\hline \multicolumn{5}{|l|}{ Illiterate (R) } \\
\hline Primary & 0.78 & 0.26 & $0.62 * * *$ & 0.09 \\
\hline Secondary and higher & 0.88 & 0.29 & $0.68 * *$ & 0.13 \\
\hline \multicolumn{5}{|l|}{ Occupation status } \\
\hline \multicolumn{5}{|l|}{ Unemployed (R) } \\
\hline Farming & 0.75 & 0.3 & $0.7 * * *$ & 0.09 \\
\hline Other & 0.85 & 0.19 & $0.77 * *$ & 0.11 \\
\hline \multicolumn{5}{|l|}{ Number of living children } \\
\hline \multicolumn{5}{|l|}{$0-2(\mathrm{R})$} \\
\hline $3-4$ & 0.99 & 0.2 & $0.81 * *$ & 0.09 \\
\hline 5 or higher & 0.93 & 0.29 & $0.74 * *$ & 0.1 \\
\hline \multicolumn{5}{|l|}{ Health care service } \\
\hline \multicolumn{5}{|l|}{ Not a problem $(\mathrm{R})$} \\
\hline Problem & 1.08 & 0.21 & 0.86 & 0.08 \\
\hline \multicolumn{5}{|l|}{ Exposure to media } \\
\hline $\begin{array}{l}\text { Neither radio nor } \\
\text { television }(\mathrm{R})\end{array}$ & & & & \\
\hline Radio or television & $0.64 * *$ & 0.22 & $0.81 * *$ & 0.08 \\
\hline Radio and television & 0.97 & 0.25 & 1.01 & 0.17 \\
\hline Women autonomy & & & & \\
\hline No $(\mathrm{R})$ & & & & \\
\hline Yes & 0.89 & 0.48 & 0.92 & 0.12 \\
\hline
\end{tabular}




\section{DISCUSSION}

Using the 2010 Malawi demographic and Health surveys, this study assesses the determinants of women's use of postnatal care in rural and urban settings in the country; first, identifying what determines women's use of postnatal care facilities and thereafter, determining the factors associated with the timing of women's use of services in Malawi. Overall, the study found low utilization of postnatal care in both rural and urban settings of the country. The significant factor associated with the low use of postnatal care services between 1 and 6 days after childbirth in the country as a whole was working as a farmer, while the significant factors associated with low use later than 1 week in both settings were: distance to healthcare facilities, lack of knowledge about pregnancy complications and exposure to either radio or television. These factors are largely linked to low socioeconomic status $^{[13,14]}$.

In addition to farming, the specific factors found to be associated with low use of postnatal care services in rural setting between 1 and 6 days after childbirth were as follows; in terms of socioeconomic factors these include low educational status, age at first birth, having 3-4 living children, and women autonomy; service-related factors include: ANC frequency, knowledge of pregnancy complications and problems associated with the availability of healthcare services ; and finally awareness-related factors mainly presented by exposure to either radio or television rather than both. It is worth noting that the rural women who had low utilization of postnatal care services had also low level of other socioeconomic factors such as low educational attainment, earning income through farming and having more living children. The findings concur with other studies reiterated that less education, inadequate awareness among women during ANC of complications and consequences of pregnancy and inability to access the facility due to distance, affected the rural women's use of postnatal care services in rural settings $[15,16]$. In most developing countries, problems of distance to access the health facilities and inadequate antenatal counselling to women predicted the low utilization of maternal healthcare services among rural women ${ }^{[17]}$.

The present study found that as women's frequency of ANC utilization is four or more times than that the WHO recommended during their pregnancy ${ }^{[17]}$, their healthcare service use after childbirth increases. This is because when women are well informed of their pregnancy complications and associated consequences by skilled practitioners during ANC visits, their subsequent use of maternal healthcare either during childbirth or thereafter increases ${ }^{[18,19]}$. This result is consistent with the study findings from other countries within the sub-Saharan African region that found ANC services as a significant initial stage to acquisition of improved maternal healthcare outcome ${ }^{[20-23]}$. The more the numbers of ANC visits made during pregnancy are related to the high risk pregnancies, the more these encourage them to pay more attention to facility care and postnatal care in the long term ${ }^{[20,24]}$.

In general, delivery by $\mathrm{CS}$ was associated with increased likelihood of women's use of postnatal care services. On the contrary, most factors in both settings reduced the likelihood of women's use of postnatal care services significantly. The significant socioeconomic factors were low educational status, problems to available transport to healthcare facilities, earning income through farming, high number of living children and age at first birth more than 20 years. On the same note, service-related factors such as problems due to distance to health facility and problems to access healthcare service facilities were influencing low use of postnatal care services in rural Malawi. Studies indicate that the situation is explained by the socioeconomic challenges that the rural and underserved communities' experiences remain barriers that prevent vulnerable women in accessing healthcare facilities ${ }^{[25,26]}$.

Furthermore, considering the rural women's access to postnatal care, the study found little variations between the factors affecting either use of postnatal care between 1 and 6 days and between 1 week and more compared with those who used postnatal care within $24 \mathrm{~h}$ after childbirth. At both times, women's use of postnatal services in rural Malawi was low among women who had problems with distance to the health facility, women who earned their living through farming, women who lacked knowledge about pregnancy complications, had low education, had more than four living children and were exposed to either radio or TV but not to both. These factors were the common factors consistently found in women of low socioeconomic status $^{[27]}$. Studies analysing the determinants of use of maternity care services in developing countries concluded that such challenges are best solved if women have essential knowledge of pregnancy complications from formal sources and receive comprehensive service delivery from skilled and resourced healthcare facilities ${ }^{[27-29]}$.

This implies that postnatal health seeking behaviour among women is still very low despite the fact that women in Malawi were found to have an increased likelihood of using other maternal healthcare services during pregnancy and childbirth ${ }^{[19]}$. Previous studies indicate that such low utilization challenge of healthcare services among women can be reduced or avoided if and only if awareness strategies aimed at enhancing individual health seeking are implemented. This is paramount if the healthseeking practice is scaled up through not only institutionalbased healthcare facilities but also through communitybased outreach care in order to meet capacity challenges affecting effective care service delivery ${ }^{[30-32]}$. This suggests the possibility of providing women-centred postnatal care using community-based nurses in order to follow up women both in rural and urban communities. Studies in Nepal and Nigeria ${ }^{[33,34]}$ found that such community-based approach encouraged women's use of healthcare services 
and subsequently improved optimal care delivery among women and new babies and subsequent use of postnatal care service facilities.

\section{CONCLUSION}

The study highlights low utilization of postnatal care in both rural and urban setting in Malawi with much lesser use in rural setting in the country. In rural areas, factors are largely linked to low socioeconomic status such as low educational status, income earned through farming and having 3-4 living children, problem of distance, inadequate knowledge about pregnancy complications and inadequate exposure to media. However, delivery by CS was associated with significantly higher use of postnatal care services within 1 week or more after childbirth. There is need to implement women-centred and communitybased awareness initiatives to enhance maternal healthseeking behaviour at both urban and rural settings. These initiatives might help in promoting community understanding of the importance of using postnatal care services after childbirth.

\section{ACKNOWLEDGEMENTS}

The authors appreciate the support of ICF Macro International under the support of United States Aid for giving the 2010 Malawi demographic and Health Survey dataset without which the paper would not have been done.

\section{CONFLICT OF INTEREST}

There are no conflicts of interest.

\section{REFERENCES}

1. Kruk ME, Galea S, Prescott M, Freedman LP. Health care financing and utilization of maternal health services in developing countries. Health Policy Plan 2007; 22:303-310.

2. World Health Organisation. Trends in maternal mortality: 1990-2015: estimates by WHO, UNICEF, the World Bank and UNFPA. Geneva, Switzerland: World Health Organization; 2015

3. Gupta D, Denton B. Appointment scheduling in health care: challenges and opportunities. IIE Transactions 2008; 40:800-819.

4. Travis P, Bennett S, Haines A, Pang T, Bhutta Z, Hyder AA, et al. Overcoming health-systems constraints to achieve the Millennium Development Goals. Lancet 2004; 364:900-906.

5. Hogan MC, Foreman KJ, Naghavi M, Ahn SY, Wang M, Makela SM, et al. Maternal mortality for 181 countries, 1980-2008: a systematic analysis of progress towards Millennium Development Goal 5. Lancet 2010; 375:1609-1623.

6. Koblinsky M, Tain F, Gaym A, Karim A, Carnell M, Tesfaye S. Responding to the maternal health care challenge: The Ethiopian Health Extension Program. Ethiop J Health Dev 2010; 24:1.

7. McNamee P, Ternent L, Hussein J. Barriers in accessing maternal healthcare: evidence from low-and middle-income countries. Expert Rev Pharmacoecon Outcomes Res 2009; 9:41-48.

8. Prata N, Ejembi C, Fraser A, Shittu O, Minkler M. Community mobilization to reduce postpartum haemorrhage in home births in northern Nigeria. Soc Sci Med 2012; 74:1288-1296.

9. World Health Organisation. Health systems financing: the path to universal coverage. Geneva, Switzerland: World Health Organization; 2015.

10. Government of Malawi. Malawi Road Map for Accelerating the Reduction of Maternal and Neonatal Mortality and Morbidity. 2007. Revised version. Ministry of Health. Capital Hill. Lilongwe.

11. Villar $\mathrm{J}$, Ba'aqeel $\mathrm{H}$, Piaggio $\mathrm{G}$, Lumbiganon $\mathrm{P}$, Belizán JM, Farnot U, et al. WHO antenatal care randomised trial for the evaluation of a new model of routine antenatal care. Lancet 2001; 357:1551-1564.

12. Van den Akker T, Beltman J, Leyten J, Mwagomba B, Meguid T, Stekelenburg J, et al. The WHO maternal near miss approach: consequences at Malawian District level. PLoS One 2013; 8:e54805.

13. Borghi JO, Ensor T, Somanathan A, Lissner C, Mills A. Mobilising financial resources for maternal health. Lancet 2006; 368:1457-1465.

14. Filippi V, Ronsmans C, Campbell OM, Graham WJ, Mills A, Borghi J, et al. Maternal health in poor countries: the broader context and a call for action. Lancet 2006; 368:1535-1541.

15. Khanal V, Adhikari M, Karkee R, Gavidia T. Factors associated with the utilisation of postnatal care services among the mothers of Nepal: analysis of Nepal Demographic and Health Survey. BMC Womens Health 2014; 14:1.

16. Palamuleni M. Determinants of non-institutional deliveries in Malawi. Malawi Med J 2011; 23:104-108.

17. Langlois E, Miszkurka M, Zunzunegui M, Ghaffar A, Ziegler D, Karps I. Inequities in postnatal care 
in low- and middle-income countries: a systematic review and meta-analysis. Bull World Health Organ 2015; 93:259-270.

18. Mrisho M, Obrist B, Schellenberg JA, Haws RA, Mushi AK, Mshinda $\mathrm{H}$, et al. The use of antenatal and postnatal care: perspectives and experiences of women and health care providers in rural southern Tanzania. BMC Pregnancy Childbirth 2009; 9:10.

19. National Statistics Office and ICF International. Malawi Demographic and health survey. Maryland, USA: Zomba, Malawi and Calverton; 2010.

20. Guliani H, Sepehri A, Serieux J. What impact does contact with the prenatal care system have on women's use of facility delivery? evidence from low-income countries. Soc Sci Med 2012; 74:1882-1890.

21. Magoma M, Requejo J, Campbell O, Cousens S, Merialdi M, Filippi V. The effectiveness of birth plans in increasing use of skilled care at delivery and postnatal care in rural Tanzania: a cluster randomised trial. Trop Med Int Health 2013; 18:435-443.

22. Sepehri A, Sarma S, Simpson W, Moshiri S. How important are individual, household and commune characteristics in explaining utilization of maternal health services in Vietnam? Soc Sci Med 2008; 67:1009-1017.

23. Thind A, Mohani A, Banerjee K, Hagigi F. Where to deliver? analysis of choice of delivery location from a national survey in India. BMC Public Health 2008; 8:29.

24. Gage AJ. Barriers to the utilization of maternal health care in rural Mali. Soc Sci Med 2007;65:1666-1682.

25. Titaley CR, Dibley MJ, Roberts CL. Factors associated with non-utilisation of postnatal care services in Indonesia. J Epidemiol Community Health 2009; 63:827-831.
26. Neupane S, Doku D. Utilization of postnatal care among Nepalese women. Matern Child Health J 2013; 17:1922-1930.

27. Gabrysch S, Campbell O. Still too far to walk: literature review of the determinants of delivery service use. BMC Pregnancy Childbirth 2009; 9:34.

28. Stephenson R, Baschieri A, Clements S, Hennink M, Madise N. Contextual influences on the use of health facilities for childbirth in Africa. Am J Public Health 2006; 96:84-93.

29. Simkhada B, Teijlingen ER, Porter M, Simkhada P. Factors affecting the utilization of antenatal care in developing countries: systematic review of the literature. J Adv Nurs 2008; 61:244-260.

30. Rosato M, Mwansambo CW, Kazembe PN, Phiri T, Soko QS, Lewycka S, et al. Women's groups perceptions of maternal health issues in rural Malawi. Lancet 2006; 368:1180-1188.

31. Kumbani L, Me Inerney P. The knowledge of obstetric complications among primigravidae in a rural health centre in the district of Blantyre, Malawi. Curationis 2002; 25:43-54.

32. Fishbein M, Yzer MC. Using theory to design effective health behaviour interventions. Commun Theory 2003; 13:164-183.

33. Pradhan YV, Upreti SR, Paratap KC, Ashish KC, Khadka N, Syed U, et al. Newborn survival in Nepal: a decade of change and future implications. Health Policy Plan 2012; 27:57-71.

34. Doctor HV, Findley SE, Ager A, Cometto G, Afenyadu GY, Adamu F, et al. Using community-based research to shape the design and delivery of maternal health services in Northern Nigeria. Reprod Health Matters 2012; 20:104-112. 